\title{
Application of bioassays and soil column test for toxicity evaluation of selected pesticides
}

\author{
A. Kungolos ${ }^{1}$, C. Emmanouil ${ }^{1}$, M. Gkantaka ${ }^{2}$, V. Tsiridis ${ }^{1}$ \\ $\&$ N. Tsiropoulos ${ }^{3}$ \\ ${ }^{I}$ Department of Planning and Regional Development, \\ University of Thessaly, 38334, Volos, Greece \\ ${ }^{2}$ Department of Environmental and Natural Resources Management, \\ University of Ioannina, Agrinio 30100, Greece \\ ${ }^{3}$ Department of Agriculture, Crop Production and Rural Environment, \\ University of Thessaly, Fytokou Str, 38446 Nea Ionia-Volos, Greece
}

\begin{abstract}
The toxic effects of an organophosphate nematicide (Fosthiazate) and a benzenoid fungicide (Metalaxyl-M) have been evaluated by the use of the fresh water algae $P$. subcapitata. The effects of copper $\left(\mathrm{Cu}^{+2}\right)$, an ingredient of many fungicidal mixtures, have also been assessed on the same organism, as well as the interactive effects of binary mixtures of the three aforementioned agrochemicals. Finally, leachates containing fosthiazate in two different concentrations have been tested on the bioluminescent bacterium Vibrio fischeri. The interactive effects of the binary mixtures were additive in most cases, while fosthiazate leachates exhibited low, dose-related toxicities.
\end{abstract}

Keywords: interactive effects, algae, bioluminescence, bioassays, fungicides.

\section{Introduction}

Agrochemicals are constantly used in high quantities in order to ensure enhanced crop yield and to decrease disease rates from various pests. Serious fungal pathogens in many cultivated plants may cause extensive damage and losses to agriculture and forestry, while plant parasitic nematodes which include several species may cause severe crop losses. Metalaxyl-M [the (-)-(R)-enantiomer of methyl- $N$-(2-methoxyacetyl)- $N$-(2,6-xylyl)-DL-alaninate] is the most widely known member of the phenylamide class of fungicides. It destroys the fungi by 
interacting with the fungal RNA polymerase I-template complex, thus inhibiting the incorporation of ribonucleotides in nascent RNA [1]. On the other hand, fosthiazate is an efficient nematicide and a member of the organophosphate class of pesticides (OPs). OPs universal mode of action is their binding to acetylcholinesterase (AChE) neurotransmitter, the inhibition of the action of this enzyme (whose function is to degrade the neurotransmitter acetylcholine), and eventually the death of the organism [2]. Finally, $\mathrm{Cu}^{+2}$ (mainly in the form of copper sulphate or "blue copper", copper oxychloride or "green copper" and cuprous oxide or "brown copper") enjoys widespread use as fertiliser or fungicide. It is of note that copper salts are also intentionally introduced into water bodies as aquatic plant herbicides, algicides and molluscicides in pest control programs around the world [3].

The contamination of the aquatic and terrestrial environment by various pesticides poses a direct risk of toxic effects on the ecosystem. Aquatic ecosystems are in particular risk since a number of chemicals are water soluble and ultimately leach towards aquatic reservoirs. An integrated evaluation of the environmental hazard of these xenobiotics necessitates the use of ecotoxicological analyses [4]. This analysis may incorporate bioassays on a number of organisms of different trophic levels, which will provide a direct measurement of toxicity in environmentally realistic concentrations. These bioassays should include a number of combinations since chemicals almost never occur in nature as single solutions but mostly as varied mixtures. Furthermore the observed toxicity is rarely the sum of the individual toxicities; phenomena such as synergistic or antagonistic effects between xenobiotics always dictate the ultimate hazard of the mixtures [5].

The objective of the present study was the evaluation of the toxic effects of three agrochemicals (fosthiazate, metalaxyl-M and copper) alone or in binary mixtures on the alga $P$. subcapitata. Furthermore, the toxicity of fosthiazate leachates, (fosthiazate is a moderately persistent nematicide which poses significant risk for groundwater contamination [6]) has been assessed on the marine bacterium Vibrio fischeri.

\section{Materials and methods}

The pesticides examined for their toxic properties were: fosthiazate and metalaxyl-M using their commercial formulations of Nemathorin and Ridomil Gold, respectively. The toxicity of copper was also evaluated using copper chloride dihydrate, $\left(\mathrm{CuCl}_{2} \cdot 2 \mathrm{H}_{2} \mathrm{O}\right)$ provided by J.T. Baker, Holland. The toxicity of both the single compounds and the binary mixtures was evaluated on $P$. subcapitata according to the Standard Operational Procedure for the Algaltoxkit $\mathrm{F}$ which follows OECD Guideline 201. A $72 \mathrm{~h}$ algal growth inhibition test was performed in triplicate in disposable long cell test vials. The algal growth inhibition was calculated for each compound concentration by measuring the optical density at $670 \mathrm{~nm}$ with the aid of a UV-Vis spectrophotometer (UV-1201, Shimadzu), after the exposure period (at $24^{\circ} \mathrm{C}$ in uniform illumination of about 8000 lux) of 24,48 and $72 \mathrm{~h}$. 
The interactive toxic effects between the three xenobiotics on P.subcapitata were also investigated and the results were statistically compared. The concentrations of the tested compounds used were obtained from the $\mathrm{IC}_{50}$ estimation experiments of each compound. The theoretically expected effect of the binary mixtures was evaluated using a simple mathematical model based on the theory of probabilities [4]. According to this model, if $\mathrm{P}_{1}$ is the inhibition caused by a certain concentration of chemical $\mathrm{A}_{1}$ and $\mathrm{P}_{2}$ the inhibition caused by a certain concentration of chemical $\mathrm{A}_{2}$, then the theoretically expected additive inhibition $\mathrm{P}(\mathrm{E})$, when those concentrations of the two chemicals are applied together, is given by the following equation [7]:

$$
\mathrm{P}(\mathrm{E})=\mathrm{P}_{1}+\mathrm{P}_{2}-\mathrm{P}_{1} \cdot \mathrm{P}_{2} / 100
$$

The null hypotheses were that the observed values were higher or lower than the theoretically predicted values, for synergistic and antagonistic effects, respectively. The result was considered to be antagonistic or synergistic only if the observed effect was significantly lower or higher, respectively, than the theoretically predicted value at $\mathrm{P}<0.05$.

The column leaching test NEN 7343 (infiltration test) was used for the evaluation of toxicity evaluation of fosthiazate in combination with soil interaction. The experiments were based on a continuous upward water flow containing 1 or $10 \mathrm{mg} / \mathrm{L}$ fosthiazate through a reference soil column for approximately 17 days. A Plexiglas column with an internal diameter of $5 \mathrm{~cm}$ was filled with $500 \mathrm{~g}$ reference soil (OECD reference soil, provided by Microbiotests Inc., Belgium), corresponding to a height of at least 4 times the internal diameter of the column. A peristaltic pump was used to continuously feed of soil column with deionized water containing $1 \mathrm{or} 10 \mathrm{mg} / \mathrm{L}$ fosthiazate under an upward water flow rate of about $10 \mathrm{~mL} / \mathrm{h}$. Seven water fractions were collected during the test, corresponding to $\mathrm{L} / \mathrm{S}$ ratio $0.1,0.2,0.5,1,2,5$ and 10 $\mathrm{L} / \mathrm{kg}$ respectively.

The toxicity of the leachates (control, $1 \mathrm{mg} / \mathrm{L}$ fosthiazate solution, $10 \mathrm{mg} / \mathrm{L}$ fosthiazate solution) was assessed by the use of the bioluminescence bacteria $V$. fischeri (Microtox test) that were in freeze-dried form (SDI, USA) and activated prior to use by a reconstitution solution. Since $V$. fischeri is a marine organism, $2 \%$ salinity was obtained, using a concentrated salt solution (solution containing $22 \% \mathrm{NaCl}$ in deionized water). The light emission of the organisms in direct contact with the samples was measured using the Microtox 500 analyzer (SDI) within a short exposure time of $15 \mathrm{~min}$. Data were processed via the Microtox Omni software (SDI). The IC50 values (the tested compound concentration that caused $50 \%$ inhibition on the bioluminescence of $V$. fischeri; expressed as $\mathrm{mg} / \mathrm{L}$ of fosthiazate, metalaxyl-M or $\mathrm{Cu}$ ) of the tested compounds were evaluated by the $45 \%$ basic test (Microbics Corp., 1992).

\section{Results and discussion}

The toxicities of the single agrochemicals and copper were first examined by applying several dilutions for each one of them on P.subcapitata and the $\mathrm{IC}_{50}$ 
value was evaluated as an endpoint. The $\mathrm{IC}_{50}$ values and the dose/response curves are given in Table 1 and Figure 1 respectively.

Table 1: $\quad \mathrm{IC}_{50}$ values and the corresponding confidence ranges for the tested compounds on $P$. subcapitata.

\begin{tabular}{lcc}
\hline \multicolumn{1}{c}{ Compound } & $\mathbf{I C}_{\mathbf{5 0}}(\mathbf{m g} / \mathbf{L})$ & Confidence range $(\mathbf{m g} / \mathbf{L})$ \\
\hline $\begin{array}{l}\text { Fosthiazate (Nemathorin) } \\
\text { Metalaxyl-M (Ridomil }\end{array}$ & 1.02 & $0.56-1.64$ \\
$\begin{array}{l}\text { Gold) } \\
\text { Copper (II) }\left(\mathrm{CuCl}_{2} \cdot \mathrm{H}_{2} \mathrm{O}\right)\end{array}$ & 24.40 & $12.70-42.30$ \\
\hline
\end{tabular}

As it is shown in Table 1, copper was the most toxic compound exhibiting the lowest $\mathrm{EC}_{50}$ value, equal to $0.05 \mathrm{mg} / \mathrm{L}$. Fosthiazate presented an $\mathrm{EC}_{50}$ value equal to $1.02 \mathrm{mg} / \mathrm{L}$, whereas metalaxyl-M toxicity was significantly lower. The toxicity to $P$. subcapitata was in the order: copper $>$ fosthiazate $>$ metalaxyl-M.

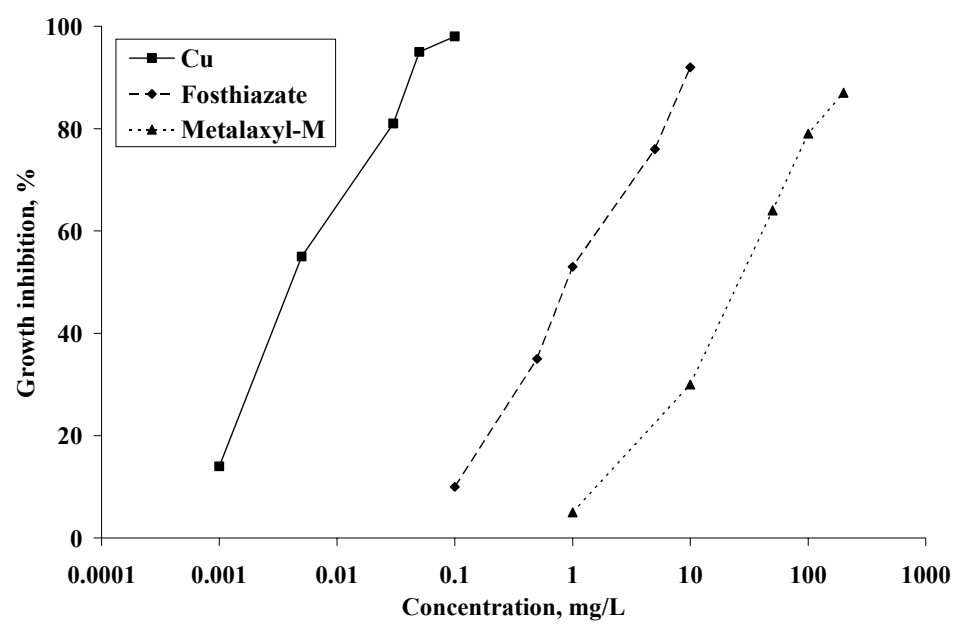

Figure 1: Growth inhibition of $P$. subcapitata after exposure to copper, fosthiazate and metalaxyl-M.

Subsequently the interactive effects between the xenobiotics were evaluated. The theoretical expected interactive effects, as calculated by Equation 1 and the observed effects for the combined action of fosthiazate and copper are illustrated in Figure 2. It can be seen that the observed effect was lower than the theoretical expected at low concentrations indicating an antagonistic action, whereas the effect was additive at higher concentrations. The theoretically expected and observed effects for the combined action of metalaxyl-M and copper on $P$. subcapitata are shown in Figure 3. The mode of interaction was generally 
additive. The theoretical expected and observed effects for the combined action of fosthiazate and metalaxyl-M are presented in Figure 4. The interactive effects for these binary mixtures were antagonistic for all concentration combinations.

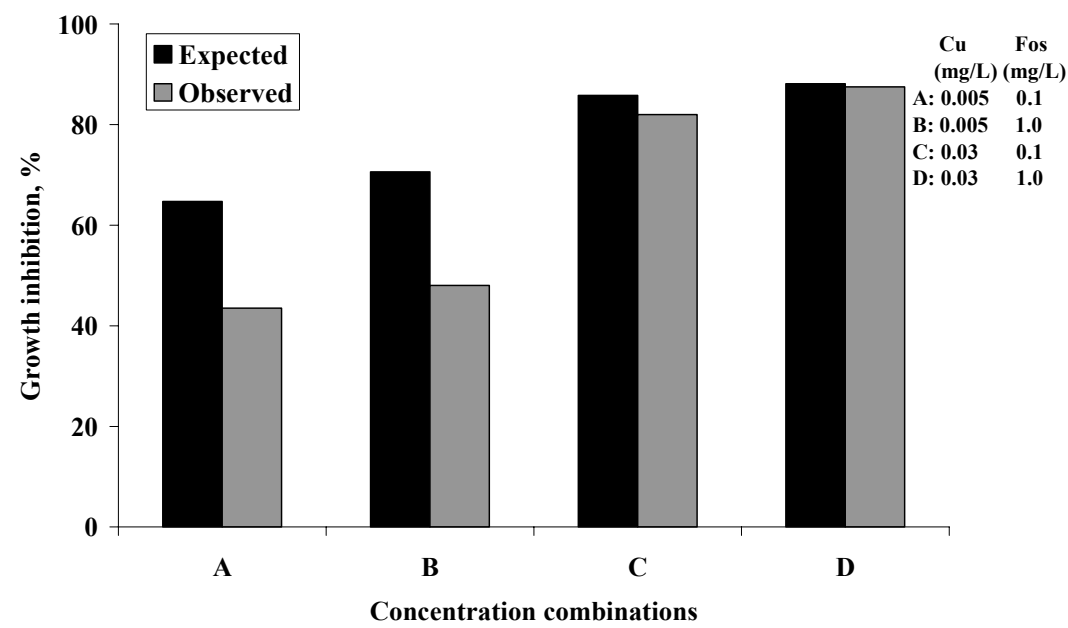

Figure 2: Comparison between theoretically expected and practically observed growth inhibition for the combined effect of fosthiazate and copper on $P$. subcapitata (key: Fos=Fosthiazate).

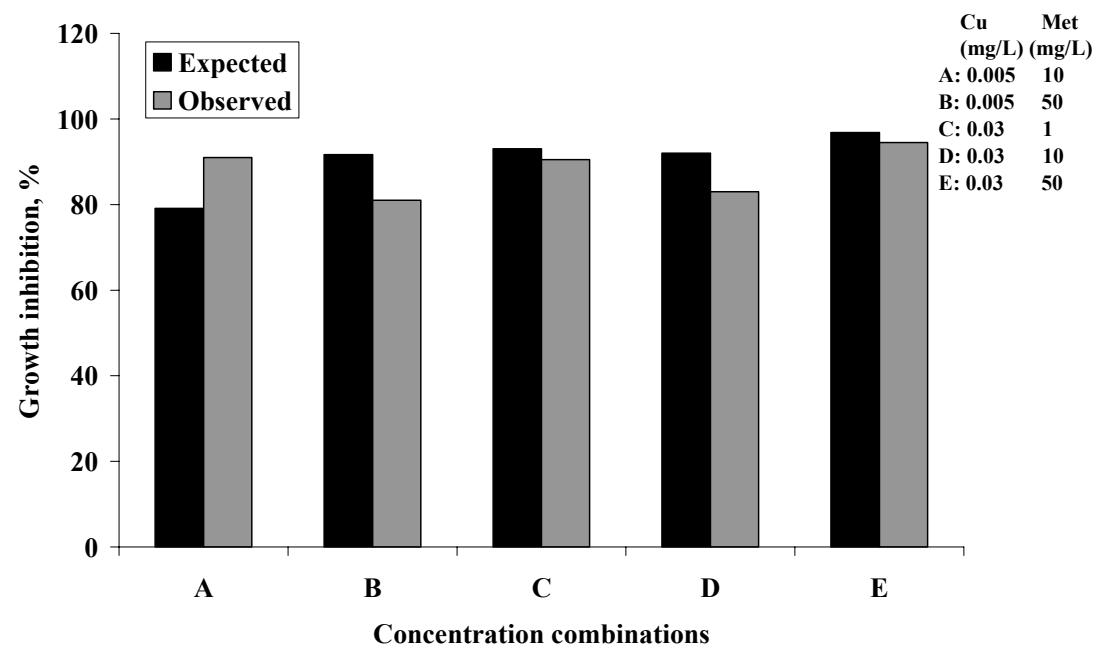

Figure 3: Comparison between theoretically expected and practically observed growth inhibition for the combined effect of metalaxyl$\mathrm{M}$ and copper on $P$. subcapitata (key: $\mathrm{M}=$ metalaxyl-M). 


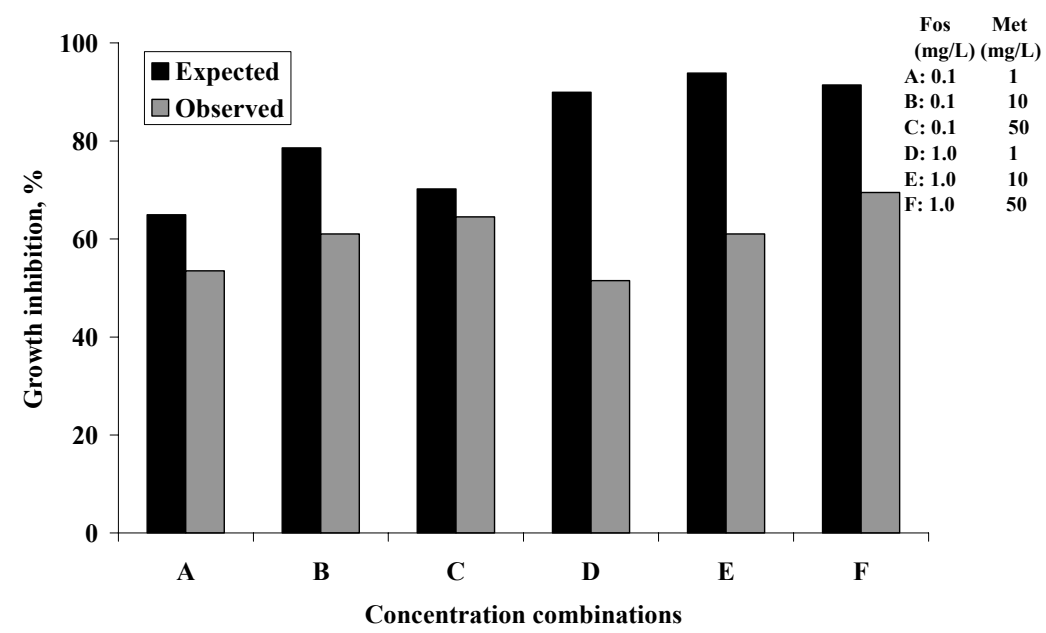

Figure 4: Comparison between theoretically expected and practically observed growth inhibition for the combined effect of fosthiazate and metalaxyl-M on P. subcapitata.

Regarding leachates of fosthiazate solutions, their toxicities were generally very low and comparable to control solution toxicities for the bioluminescent bacterium Vibrio fischeri. It is worth mentioning that a relatively high concentration of fosthiazate $(10 \mathrm{mg} / \mathrm{L})$ produced a more significant toxicity to the bacterium, at low leachate volumes.

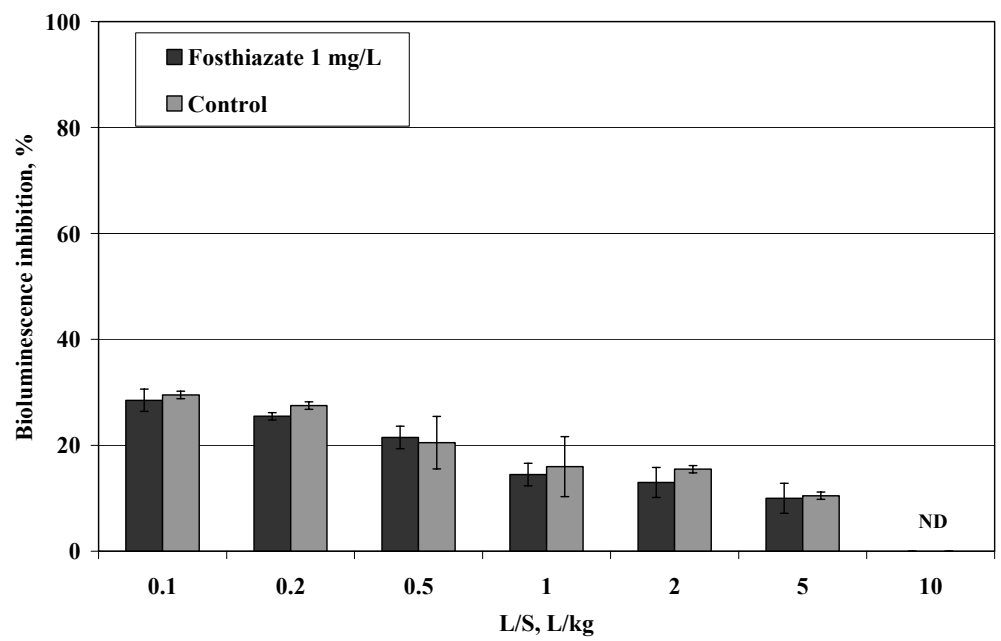

Figure 5: Bioluminescence inhibition of Vibrio vischeri after exposure to control leachate and to leachate from a $1 \mathrm{mg} / \mathrm{L}$ fosthiazate solution, in relation to leachate volume. 


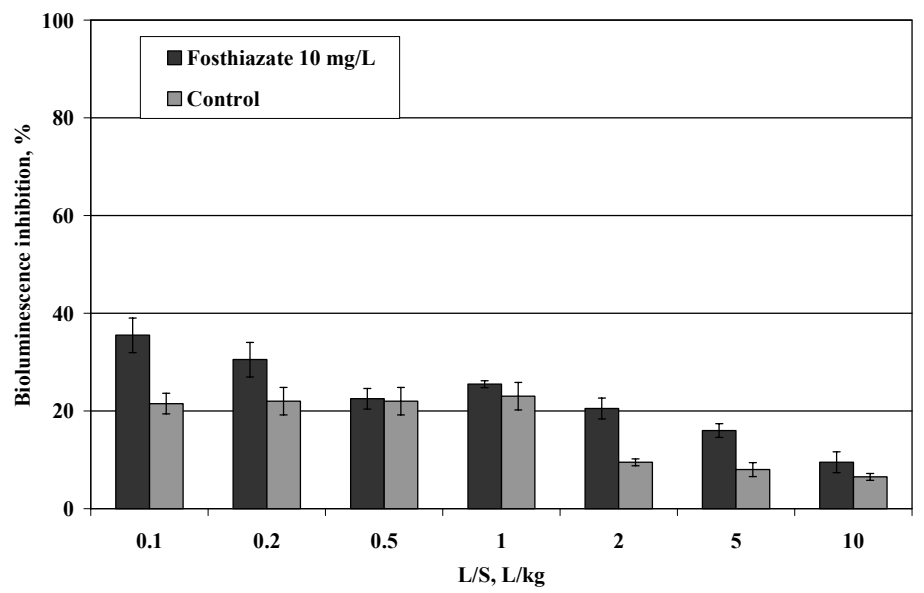

Figure 6: Bioluminescence inhibition of Vibrio vischeri after exposure to control leachate and to leachate from a $10 \mathrm{mg} / \mathrm{L}$ fosthiazate solution, in relation to leachate volume.

\section{Conclusions}

In this study, $P$. subcapitata has been successfully used to evaluate the acute toxicities of three agrochemicals: fosthiazate, metalaxyl-M and copper (II). Copper exerted an antagonistic effect towards fosthiazate at low doses and an additive effect at high doses as well as an additive effect towards all doses of metalaxyl-M. On the contrary, the combination between fosthiazate and metalaxyl-M produced antagonistic results at all doses. Thus, certain combinations of the present agrochemicals may reduce their combined toxic potential. At this point the antagonistic or the synergistic results of the agrochemicals cannot be readily explained. Copper ions are able to react with sulphydryl groups disrupting a number of enzyme-active sites in algae [8] and may also react with S-containing molecules such as fosthiazate, explaining up to a point its antagonistic action. A similar interaction between the well-known -SH ligand $\mathrm{Hg}^{2+}$ and the organophosphate chlopyrifos has already been noted [9]. The induction of murine cytochrome isoforms by metalaxyl [10] may also be responsible for faster catabolism (and reduced activity) of fosthiazate, provided that similar isoforms exist in algae. Furthermore, leachates from fosthiazate, a nematicide with relatively high leaching potential, verified the leaching properties of the nematicide which, however, here exhibited average toxicity towards Vibrio fischeri.

\section{References}

[1] Marucchini C., and Zadra C., Stereoselective degradation of Metalaxyl and Metalaxyl-M in soil and sunflower plants. Chirality, 14, 32-38, 2002 
[2] Fukuto T.R., Mechanism of action of organophosphorus and carbamate pesticides, Environmental Health Perspectives, 87, 245-254, 1990

[3] WHO. Copper. Environmental Health Criteria 200. IPCS-International Programme on Chemical Safety, WHO, Geneva, 1998.

[4] Kungolos A., Samaras P., Kipopoulou A.M., Zoumboulis A. and Sakellaropoulos G.P., Interactive toxic effects of agrochemicals on aquatic organisms' Water Science and Technology, 40 (1), 357-364, 1999.

[5] Hadjispyrou S., Kungolos A. and Anagnostopoulos A., Toxicity, bioaccumulation and interactive effects of organotin, cadmium and chromium on Artemia franciscana. Ecotoxicology and Environmental Safety, 49, 179-186, 2001.

[6] Karpouzas D.G., Pantelidis I., Menkissoglu-Spiroudi U., Golia E., and Tsiropoulos N., Leaching of the organophosphorus nematicide fosthiazate. Chemosphere, 68, 1359-1364, 2007.

[7] Sanders D.H., Eng R.J. and Murph A.F., Statistics, a fresh approach. McGraw-Hill Company, New York, 1985.

[8] Stauber J.L., and Florence T.M., Mechanism of toxicity of ionic copper and copper complexes to algae. Marine Biology, 94, 511-519, 2004.

[9] Steevens J.A., and WH Benson, Toxicological interactions of chlorpyrifos and methyl mercury in the amphipod, Hyalella azteca. Toxicological Sciences, 52, 168-177, 1999.

[10] Paolini M, Mesirca R, Pozzetti L, Sapone A, Cantelli-Forti G., Biomarkers of effect in evaluating metalaxyl cocarcinogenesis. Selective induction of murine CYP 3A isoform. Mutation Research, 361, 157-164, 1991. 